\title{
EL RETO DE LA INTERCULTURALIDAD: Interculturalidad, plurinacionalidad y ciencias sociales en el Ecuador'
}

Susana Andrade $e^{2}$

\section{Resumen:}

En la carrera hacia la modernidad y el progreso, buscando ser más occidentales y blancos fuimos despreciando nuestro conocimiento y negando nuestro color de piel. Sin embargo, los pueblos indígenas, negros y montubios, quienes más han soportado el peso de la opresión, la discriminación y la injusticia, han sabido resistir los procesos de destrucción cultural a través de respuestas creativas; unas veces activas (sublevaciones), otras pasivas (conversión religiosa, migración). Su lucha continua, perseverante y optimista ha alcanzado por fin el reconocimiento, respeto y valoración cultural con la declaración constitucional del Ecuador en 2008 como país pluriétnico e intercultural.

Este es el inicio de un nuevo tiempo, una batalla se ha ganado pero recién empieza el reto de saber el significado concreto de estos principios y cómo deberán ser abordados en la vida cotidiana y en las políticas públicas. Estas nociones, también constituyen un cuestionamiento para las ciencias sociales, interpeladas por los movimientos sociales por su ligereza y recelo hacia el conocimiento local.

Este artículo hace un repaso rápido sobre estos temas, recordando que se requiere revisar la historia para una mejor comprensión de los procesos de lucha social que llevaron al Ecuador a declarar su plurinacionalidad e interculturalidad.

\begin{abstract}
In a race towards modernity and progress, trying to be whiter and more western, we undervalued our own knowledge, ignoring our skin color. Regardless, the indigenous, blacks and montubios, who bore the most of the weight of discrimination and injustice have resisted the processes of cultural destruction through creative responses, sometimes active (subversion) others passive (religious conversion, migration). Their continual fight, persevering and optimistic, finally achieved recognition, respect, and cultural value in 2008 with Ecuador's constitutional declaration as a plural-national and intercultural country. This is the beginning of new times: the battle has been won, but the challenge of knowing the correct meaning of
\end{abstract}

1 Una versión anterior de este artículo se elaboró para el seminario: Políticas Públicas e Interculturalidad, realizado en Quito, el 25 y 26 de junio 2009, organizado por el Ministerio Coordinador de Patrimonio Natural y Cultural, y Naciones Unidas, Fondo para el logro de los ODM.

2 Escuela de Antropología, PUCE. 
these terms and how they should fit into everyday life and public policy has just begun. These ideas also constitute a questioning of the social sciences on the part of social movements who question the latter's suspicion and hesitance towards local knowledge.

This article makes a light review of these themes, reminding that history needs to be revised in order to develop a better understanding of the processes of social struggle that lead Ecuador to declare its plurinationality and interculturality.

. 1 tema de la interculturalidad necesita ser abordado desde una perspectiva histórica y por eso es muy importante definir algunos elementos del proceso de colonización. Cuando nos referimos a la colonización, no solamente hablamos del período de colonización política española desde el siglo XVI hasta el siglo XVIII. La colonización continuó durante el período de la independencia y se ha prolongado hasta hoy a través de los actuales modelos de desarrollo económico.

Desde la llegada de los españoles a América, el saqueo de recursos naturales desde América hasta Europa y más tarde a Estados Unidos ha sido continuo. Las relaciones de producción fueron y siguen siendo de explotación, desiguales, vendemos nuestros recursos y los compramos nosotros mismos pero a precios más altos: oro, plata, caucho, caña de azúcar, petróleo, etc.

En lo ideológico, religioso y cultural, los países colonizadores se consideraron los representantes de la civilización, del progreso; seres superiores que venían a imponer su orden en todos los campos, los oficios y las actividades. Lo local representó lo inferior, lo salvaje, lo incivilizado que había que cambiarlo. De allí nace el problema de identidad generado por esta ideología colonizadora que rechazó contundentemente lo americano, lo indígena, lo negro especialmente, pero también las mezclas de lo cholo, lo montubio, lo mulato.

Esta dicotomía superior-inferior fue interiorizada por ambas culturas. Las culturas locales pasaron a identificarse como seres inferiores, quienes tenían lo que merecían: el maltrato, la violencia, el desprecio de sus amos y señores. Había que parecerse a ellos para gozar de alguna ventaja, tanto en la apariencia como en los gustos y costumbres y maneras de pensar. Este proceso se lo conoce como "blanqueamiento": borrar las identidades cobrizas, mestizas, negras, indígenas e intentar parecerse al blanco explotador para lograr alguna ventaja, algún derecho.

Por eso podemos encontrar al interior de los pueblos serranos, costeños y amazónicos núcleos de población "blanca" que desprecian y explotan tenazmente a las poblaciones locales sólo por el hecho de ser "más blancos".

Desde el punto de vista de las culturas indígenas, el mecanismo de sobrevivencia ante la injusticia y la explotación ha sido la segregación, el aislamiento, la separación, la autarquía, el retiro. Ello implicó considerarse diferentes, de allí la existencia de pueblos de indios y pueblos de blancos, iglesias de indios, iglesias de blancos, cementerios de indios y cementerios de blancos; diferencias que los separaron diametralmente por políticas de discriminación y auto-exclusión. 
Para los pueblos indígenas, el orden, la armonía, la humanidad, estuvo de su lado; frente al desorden, la injusticia, la incomprensión del mundo de los blancos, un mundo casi inmoral, inhumano, que no respetaba a los animales, a las plantas, a los astros, a las montañas y menos aún al hombre y la mujer andina, negra.

A través de quinientos años no ha habido formas de acercamiento pacíficas ni voluntarias entre las diferentes culturas en el Ecuador, los gobiernos han representado los intereses y la mentalidad de la cultura blanca-mestiza (monocultural). Las políticas económicas han estado dirigidas a borrar las diferencias culturales. Los modelos económicos han tenido como referente el hemisferio norte; han visto en lo occidental el camino a seguir y de allí que han existido tantos intentos fracasados, intentos "bien intencionados" por modernizar la economía, la política, la cultura, las mentalidades.

La reacción de las 'otras' culturas al perder el control de sus vidas, ha sido el de oponerse a los cambios, actitud que ha sido vista como reacción propia de salvajes, ignorantes. Este rechazo a los cambios no debe ser analizado como rechazo a la modernización y apego a la tradición. Ésta sería una visión muy simplificada de un fenómeno más complejo. No es que las culturas indígenas, negras, montubias rechacen las innovaciones, las nuevas tecnologías, las transformaciones que acarrea la globalización. Desde la colonia española, las innovaciones fueron aceptadas, incluso apropiadas y las diferentes culturas decidieron que elementos tomar de la cultura dominante y que elementos desechar. Esta lógica la hemos podido observar en todos los campos: en el de las creencias se ha venerado a unos santos y vírgenes sobre otros, en los ritos, en los alimentos, en el intercambio, en las formas de organización social y política, en las costumbres, en las ideas, en las palabras y en los gestos ha habido una agencia cultural indígena, negra, montubia.

Han existido formas activas de selección de elementos provenientes de la cultura del colonizador que se han "indigenizado", siempre y cuando el control de este proceso ha estado en sus manos, ha sido su decisión adoptar o desechar tal o cual técnica agrícola, producto, santo o virgen en cuestión. La imposición ha generado reacción, resistencia, rechazo.

\section{La colonización de los saberes}

Si continuamos analizando el proceso de colonización, aún vigente, no podemos olvidar que en el campo de las ideas y el conocimiento éste se ha manifestado ampliamente. Al interiorizar a las "otras" culturas, se sometieron sus saberes, su lengua, su espíritu, sus símbolos y sus ritos milenarios a la cultura dominante. Aquella tan bien lograda relación entre el ser humano y la naturaleza, propia de las culturas "paganas", pasó por alto a los colonizadores quienes en el mejor de los casos la percibieron como "superstición" o brujería. Y bajo este concepto se perdió no sólo el respeto y control del medio ambiente sino también técnicas de cacería y recolección, conocimientos sobre ciclos agrícolas, calendarios astronómicos relacionados a la caza, a la pesca, a la agricultura y a los manejos del espacio. En el campo social y político la lista es grande pues desconocieron formas de 
gobierno “consensuadas", igualitarias, democráticas, de las cuales occidente pudo haber aprendido mucho.

El único y válido conocimiento sólo provino de la cultura del opresor, así como de sus técnicas de producción, formas de autoridad jerárquicas y autoritarias, fe y ritos cristianos. Conocimientos que poco a poco no permitieron el control de las poblaciones locales sobre sus propios destinos; conocimientos que más tarde se relacionaron con cambios en los patrones de consumo, en el uso de agroquímicos, en la dependencia a los mercados nacionales e internacionales; en definitiva cambios que provocaron dependencia, obediencia y sumisión a nuevas formas de colonización.

La gran barrera de racismo, la discriminación y el etnocentrismo influyó también en el uso del Quichua y otros idiomas indígenas, en el vestido, las fiestas. Se prohibió dentro del sistema educativo público hablar las lenguas vernáculas, utilizar la vestimenta indígena; a los hombres se les cortó el cabello trenzado y a los niños se les castigó cuando hablaban su idioma materno. La Iglesia Católica cómplice de estas políticas educativas y culturales monocéntricas, organizó internados para separar a los hijos de sus padres y alcanzar una desconexión cultural para evangelizarlos y educarlos efectivamente.

Con la independencia de España y la creación de la República del Ecuador en 1830, la situación no cambió respecto a las culturas oprimidas; todo lo contrario, las políticas de destrucción cultural se fortalecieron bajo los conceptos de la Revolución Francesa de "libertad, igualdad y fraternidad". El referente continuó siendo Europa, con los movimientos de la ilustración, el positivismo y el romanticismo.

La Constitución ecuatoriana de 1830 expresaba claramente quiénes eran los ciudadanos ecuatorianos.

Art. 12. "Para entrar en el goce de los derechos de ciudadanía se requiere: 1) Ser casado, o mayor de veintidós años, 2) Tener una propiedad raíz, valor libre de 300 pesos y ejercer alguna profesión, o industria útil, sin sujeción a otro, como sirviente doméstico o jornalero.

3) Saber leer y escribir".

Art. 68. "Este Congreso Constituyente nombra a los venerables curas párrocos por tutores y padres naturales de los indígenas, excitando su ministerio de caridad a favor de esta clase inocente, abyecta y miserable". (Constitución del Ecuador, 1830).

\section{Nuevas formas de colonización}

Las nuevas formas de colonización están regidas por la economía de mercado. El modelo de desarrollo económico neoliberal capitalista, ha estado vigente desde los años 60 y sigue siendo de naturaleza extractiva y agro-exportador con las negativas consecuencias ambientales, sociales y culturales ya mencionadas. El mercado ha reducido y homogenizado la producción agrícola. De las veinte variedades de papa que producía la provincia del Carchi en 1996, hoy produce sólo dos variedades: la chola y la superchola, y a ello le acompaña el incremento de uso de agroquímicos y los consecuentes problemas ecológicos y de salud (Queiroz, 2009: 6). Así hay muchos ejemplos más sobre la destrucción de culturas milenarias asociadas al modelo de desarrollo económico capitalista, donde se han 
perdido los conocimientos ancestrales sobre el uso de la tierra, el agua, el espacio, las formas de trabajo comunitarias y las creencias religiosas, entre algunos saberes.

\section{Resistencia y descolonización}

Estos procesos de sometimiento, desconocimiento y colonialidad han estado contestados permanentemente por los pueblos y nacionalidades del Ecuador bajo diversas formas. Unas veces las respuestas fueron activas a través de levantamientos, paros, invasiones; y otras veces fueron pasivas a través de una lucha silenciosa por conservar su patrimonio cultural, sus valores, sus creencias, sus sueños y esperanzas. Las luchas han estado dirigidas a la demanda de derechos legítimos e históricos por la tierra, los recursos naturales, el respeto, la justicia y sobre todo por el reconocimiento de la diferencia: "Tenemos el derecho a ser iguales cuando la diferencia nos interioriza, tenemos el derecho a ser diferentes, cuando la igualdad nos descaracteriza" (Sousa Santos, 2009: 60).

La resistencia intencional a los modelos de modernización que comenzaron en los años 40 y continúan hasta hoy, se han expresado en un rechazo a ser incorporados a un modelo de desarrollo individualista, rentista, mercantilista, deshumanizado, totalmente ajeno a sus valores, objetivos y metas destinados a alcanzar el bienestar, no solamente económico sino social y espiritual. Además la negativa a modernizarse, ha sido una negativa a la forma de implementación de los proyectos de desarrollo: una forma vertical, desde arriba, sin participación alguna de los beneficiarios en ninguna de las fases de los proyectos (diseño, gestión). La tónica fue la imposición de ideas y proyectos. El colonizador pensó saber con certeza lo que le convenía a los subordinados. De allí que ingentes recursos y proyectos "productivos" fracasaron. Así como letrinas convertidas en bodegas, cuyeras en letrinas, viveros en campos de batalla de los comuneros y máquinas textiles destruidas ( Andrade, 1990: 63).

Las formas de organización indígena, negra y montubia, por lo tanto, estuvieron presentes desde el inicio de la llegada de los conquistadores y siguen presentes, afortunadamente muchas rebeliones están documentadas (Segundo Moreno, 1978).

El proyecto de transformación social y política y de cambio de estructuras de pensar ha sido y es la meta de la descolonización: "Libramos múltiples luchas y batallas contra la mentalidad colonial que no nos reconocía y no nos reconoce" (Macas, 2009: 82).

La adaptación y reinterpretación de elementos o influencias externas, provenientes de la cultura dominante han sido otras formas de resistencia, es decir, ha existido una apropiación de ciertos elementos no indígenas para hacerlos suyos y así poder reproducir, en la mezcla, la cultura y la identidad.

Uno de los ejemplos más extraordinarios han sido los procesos de conversión religiosa tanto al catolicismo en el siglo XVI como al protestantismo moderno. La recreación de ideas, ritos, espacios, historias y dogmas ha sido continua. De allí que existe un protestantismo indígena, un catolicismo popular que dista mucho de sus orígenes y mentores.

Otros ejemplos sorprendentes han sido la inserción en el mercado informal, los procesos de migración interna y externa y otras formas de convivencia con la cultura globalizada para poder sobrevivir.

Lentamente surgiría una propuesta colectiva, fruto de las luchas locales, que reivindicaría los derechos colectivos, el rescate de la justicia y la descolonización de la historia; proceso mediante el cual era importante visibilizar las injusticias, la marginación, 
la discriminación de los pueblos y nacionalidades a lo largo de la historia, ocultando el rol central de los pueblos en el sostenimiento de la economía nacional a través del tributo y la explotación de la fuerza de trabajo indígena, negra y montubia.

\section{La plurinacionalidad}

El Estado plurinacional fue una propuesta de la Confederación de Nacionalidades Indígenas del Ecuador (CONAIE), que surgió en los años 80 y reclamaba el reconocimiento de las nacionalidad indígenas, negras y montubias, en igualdad de condiciones a la nacionalidad mestiza. Es un proyecto que desafió al Estado uninacional, el cual sólo ha representado a los sectores dominantes; el Estado plurinacional "reconoce, respeta y promueve la unidad entre todos los pueblos y nacionalidades indígenas, negras y montubias" (CONAIE, 2007) y ha sido definido por la CONAIE como:

“...un modelo de organización política para la descolonización de nuestras naciones y pueblos que desecha para siempre las sombras coloniales y monoculturales desde hace casi 200 años" (CONAIE, 2007).

La propuesta de construir un Estado plurinacional planteó una lucha estructural, decolonial, dirigida a la creación y construcción de una nueva sociedad con justicia, equidad, dignidad.

Frente a la presión de los movimientos sociales, especialmente indígenas, la Constitución de 1998 reconoció la existencia de pueblos indígenas y negros e incluyó el reconocimiento de quince derechos colectivos a estos pueblos.

La nueva Constitución del 2008 finalmente aprobó en el artículo $1^{\circ}$ que: "El Ecuador es un estado constitucional de derechos y justicia social, democrático, soberano, independiente, unitario, intercultural, plurinacional y laico" (Constitución del Ecuador, 2008).

La idea de plurinacionalidad conlleva la de interculturalidad. Ésta última es la herramienta para alcanzar la meta de la plurinacionalidad. Un estado plurinacional que respeta las diferentes culturas, tiene que traducir ese reconocimiento en políticas públicas concretas que se guíen bajo el eje de la interculturalidad o diálogo entre culturas. Sobre este tema, el líder shuar Ampan Karankras manifiesta que:

“...la plurinacionalidad sirve para caracterizar una situación y la interculturalidad describe una relación entre culturas. No puede existir solo interculturalidad, hay que complementarla con la plurinacionalidad, el uno sin el otro, no existe" (Karankas, 2009).

Antes de proseguir con el tema de la interculturalidad definamos algunos conceptos claves que nos ayudarán a entender mejor el significado de esta noción. La CONAIE define a los grupos indígenas como "pueblos y nacionalidades". Existen catorce nacionalidades y dieciocho pueblos, entre los cuales están los quichuas, shuar, achuar, cofanes, sionassecoyas, huaoranis, tzachilas, chachis, awa, epera, afroecuatorianos, mestizos. Dentro de la nacionalidad quichua, por ejemplo, se incluye a los pueblos; cayambis, otavalos, salasacas, saraguros, cañaris, quitu-caras y otros. 
Las nacionalidades están definidas como:

“...entidades históricas y políticas que tienen en común una identidad, historia, idioma, cultura propia y territorio en el cual han ejercido formas tradicionales de organización social, económica, jurídica, política y de autoridad" (CONAIE, 1997).

También, se caracteriza a los pueblos como:

“...colectividades cohesionadas por un conjunto de factores, ocupan un territorio definido, hablan una lengua común, comparten una cultura, una historia y aspiraciones comunes, factores que les diferencia de otros pueblos. Diferencia de pueblos y nacionalidad indígenas no es sólo cultural sino histórica, política y económica" (CONAIE, 1997).

En cuanto al concepto de cultura, encontramos un sin número de definiciones, una de las más apropiadas la define como:

“...un conjunto de estigmas que tiene un grupo a los ojos de otro. Según el poder del otro, esta imagen alienada exige una respuesta que puede ser la negación o los diversos renacimientos étnicos a través de los cuales un pueblo reconstruye dichos estereotipos y los reafirma en una nueva política cultural, algo que jamás es el retorno a una realidad auténtica previa sino siempre una nueva construcción. La cultura sería un vehículo o medio por el cual se negocia la relación entre los grupos" (Jameson, 1998: 102).

Este proceso es el que parece tener lugar en el Ecuador, pues se halla en plena reconstrucción la cultura y la identidad indígena, afroecuatoriana y montubia- basada en los nuevos conceptos de pueblo y nacionalidad, de ciudadanía -no relacionada únicamente con los derechos individuales sino también colectivos-, en la crítica a los términos indígena y negro como expresiones racistas y homogenizantes, las mismas que empiezan a ser reemplazadas por términos más adecuados: "el término indígena es neocolonialista pues cada pueblo tiene su identidad" (Karankras, 2009). El presidente de la corporación de desarrollo afroecuatoriano (CODAE), ha declarado la nulidad del término "negro" para denominar a la población afroecuatoriana por su connotación racista y negativa (Chalá, 2009).

La nueva reconstrucción de las culturas e identidades -indígena, montubia afroecuatoriana, mestiza- parte de una simbiosis entre elementos tradicionales y modernos; entre distintas formas de conocimiento, maneras diferentes de vivir, mezcla de cosmovisiones, música y tradiciones. Esta reconstrucción de estereotipos, con un poco de mezclas culturales, apropiación de elementos no indígenas sumados a los indígenas (o afroecuatorianos y montubios) es lo que produce la nueva identidad y cultura. "Estamos aquí siendo, haciendo, sintiendo", es el lema del pueblo quichua "Kitu Kara", en su búsqueda de una identidad perdida, reencontrada, convenida, reinventada. Lo importante es el orgullo y la revalorización de sus orígenes indígenas que por siglos fueron encubiertos, negados por ellos y por la sociedad racista y excluyente. Hoy son orgullosos del color de su piel, de sus 
apellidos que revelan su origen indio, de su patrimonio y herencia cultural así como de sus tatuajes y música metal que también forman parte de su identidad. Ver el siguiente afiche:

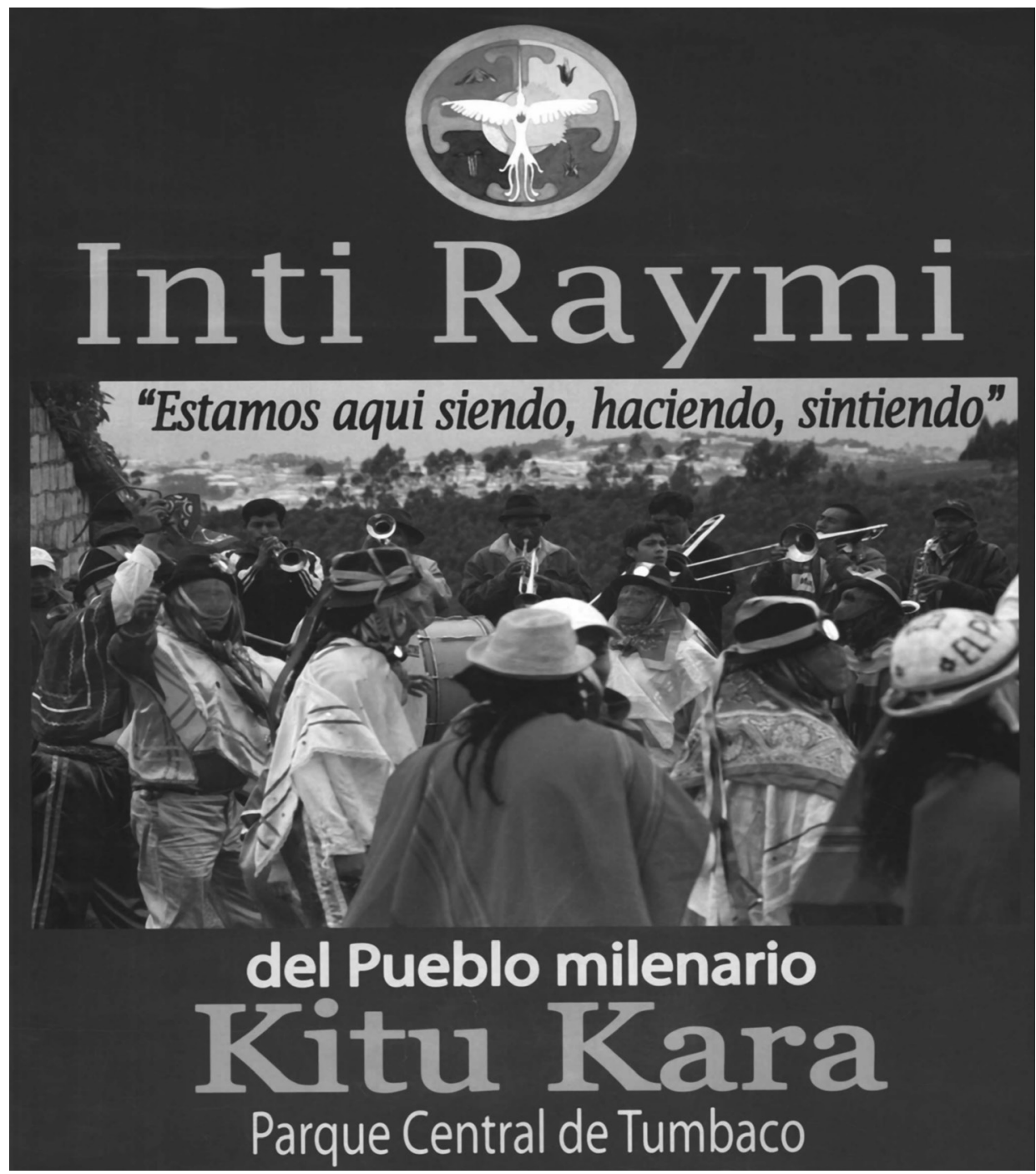

\section{La interculturalidad}

En una definición simple podemos decir que la interculturalidad es un proyecto de diálogo entre diversas culturas. A través de ella se pretende construir una nueva relación social, más igualitaria, sin discriminación, de respeto entre grupos y personas que pertenecen a diferentes culturas. Este concepto desafía al colonialismo y al racismo aún 
vigentes, expresados en el trato que se da a los indios y afroecuatorianos en la calle, en el mercado, en los buses, en las escuelas y otros espacios.

La interculturalidad va de la mano con la intraculturalidad, con el proceso de autodefinición de las nuevas identidades que acabamos de explicar. Sólo sabiendo quiénes somos podremos relacionarnos con los otros y demandar el respeto y los derechos que merecemos.

A nivel político, la interculturalidad se plantea como una herramienta de transformación del Estado y la sociedad pues exige cambios en todos los niveles de las políticas públicas y de la sociedad civil para transformar las antiguas estructuras socio-políticas-coloniales e iniciar procesos de inclusión de los sectores culturalmente marginados. Ésta sería la interculturalidad geopolítica y descolonizadora donde "compartir el poder es esencial, todo lo demás es discurso" (De la Cruz, 2009). Los pueblos y nacionalidades han venido exigiendo representación en los organismos oficiales como una manera concreta para asegurar los procesos de inclusión. Se oponen a la interculturalidad retórica, que desde la constitución de 1998 ha quedado en simples enunciados.

Constitución del Ecuador de 1998. De la cultura

“Art. 62.- La cultura es patrimonio del pueblo y constituye elemento esencial de su identidad. El Estado promoverá y estimulará la cultura, la creación, la formación artística y la investigación científica. Establecerá políticas permanentes para la conservación, restauración, protección y respeto del patrimonio cultural tangible e intangible, de la riqueza artística, histórica, lingüística y arqueológica de la nación, así como del conjunto de valores y manifestaciones diversas que configuran la identidad nacional, pluricultural y multiétnica. El Estado fomentará la interculturalidad, inspirará sus políticas e integrará sus instituciones según los principios de equidad e igualdad de las culturas.

Art. 69.- El Estado garantizará el sistema de educación intercultural bilingüe; en él se utilizará como lengua principal la de la cultura respectiva, y el castellano como idioma de relación intercultural" (Constitución del Ecuador, 1998).

Si bien la noción de interculturalidad ya se encuentra vigente en la constitución desde 1998, como podemos ver, las políticas e instituciones del Estado no han reflejado "los principios de equidad e igualdad de las culturas"; la relación ha sido asimétrica. ¿Cómo volver simétrico el diálogo intercultural? Una propuesta es fomentar una interculturalidad por doble vía, cuando, por ejemplo, el grupo mestizo aprenda quichua o shuar o cualquier otra lengua indígena, o cuando la cultura dominante profundice el conocimiento de las "otras" culturas, vislumbrando la relación que existe con la naturaleza, o comprendiendo las formas de comunicación y respeto que mantienen con los espíritus de la naturaleza para cazar, sembrar, cosechar. Sólo en el momento en que aprendamos a escuchar al viento, hablar con el mar, y reír con las aves podremos conocer y respetar las culturas milenarias, que a pesar de la violencia sufrida, siguen presentes, vitales, cuestionando las malas prácticas del racismo, la corrupción, la injusticia, la intolerancia, y la discriminación de la cultura dominante. De allí que el concepto de interculturalidad constituye un conceptofuerza que nos ayuda a conectar con ideas, ideales y situaciones a alcanzar. 


\section{¿Cómo abordar la interculturalidad?}

La interculturalidad tiene que ser un instrumento de descolonización. La construcción de un Estado plurinacional y de una democracia intercultural desafían al Estado monocultural, a la democracia liberal y al sistema jurídico unitario y proponen la combinación de experiencias de formas occidentales y no occidentales para redefinir formas nuevas de justicia, un concepto más adecuado de ciudadanía, de los derechos humanos, del reconocimiento a una doble identidad (local y nacional).

Para resolver las dificultades y contradicciones que se presenten entre la nueva declaración constitucional de Estado plurinacional e intercultural, el reconocimiento de derechos colectivos y las leyes y prácticas nacionales e internacionales será muy importante el papel que asuman los nuevos tribunales y consejos de interculturalidad.

Con respecto a la educación, si bien la noción de interculturalidad nació en los años 70 a raíz del programa de educación bilingüe intercultural, la reestructuración institucional de este programa deberá dirigirse a ajustar los desequilibrios entre idiomas, la falta de armonía entre los deseos y necesidades de las familias y los recursos y estructura de las escuelas y las presiones del mundo externo. Es imperativo fortalecer el sistema educativo para evitar su politización, proveyendo de recursos a las escuelas y de materiales educativos en lenguas indígenas. La capacitación lingüística y cultural de los profesores mestizos es de suma importancia como lo demuestra la valiosa experiencia de la Educación Bilingüe Intercultural (EBI) en estos cuarenta años de existencia. De igual manera, habrá que aprender de las experiencias en los diversos campos donde se han aplicado proyectos interculturales como es el caso de la salud. El hospital San Luis de Otavalo es un ejemplo en este sentido, de fortalezas y debilidades en la combinación de dos sistemas de representación cultural de la salud (Rodríguez, 2009).

En fin, el Gobierno Nacional deberá reestructurar los ministerios bajo estrategias de reorganización interna, que empiecen por el reconocimiento de las diversas culturas e incluso deberá considerar cambiar los nombres de algunas instituciones como por ejemplo el Ministerio de Cultura por el de Ministerio de Culturas, o el Ministerio de Salud por el de Ministerio de Sistemas de Salud del Ecuador.

\section{Interculturalidad y Ciencias Sociales}

Finalmente quisiera realizar una breve digresión sobre el impacto que ha tenido la noción de interculturalidad en las ciencias sociales, particularmente en las universidades. En primer lugar cabe aclarar que el proyecto de interculturalidad fue propuesto por el movimiento indígena ecuatoriano y no concebido desde la academia.

La movilización política indígena de los 90, permitió la insurrección del conocimiento al cuestionar las formas hegemónicas (occidentales) de conocimiento. Es decir, tuvo lugar una sublevación de los saberes locales definidos por la ciencia, como locales, ilegítimos e inferiores. La antropología ha tenido que reconocer y realizar una "mea culpa" sobre su origen y práctica colonial al haber designado a las culturas indígenas como su "objeto" 
de estudio y haber pretendido representarlas a nivel político. Hoy reconocemos a las culturas indígenas como sujetos que hablan, piensan y saben, destacando las posibilidades de su auto-entendimiento y acción. Son agentes activos que no necesitan de ventrílocuos académicos para hablar y actuar. El quehacer antropológico no deberá ser más "sobre" las culturas y los movimientos sociales, sino "con" ellos.

Su disposición será contribuir a visibilizar otras formas de conocimiento, a aprender y reivindicar el conocimiento periférico. El objetivo será trabajar con los centros alternativos de conocimiento como la Universidad Intercultural Amauta Wasi o la Fundación Kausay, los centros culturales, artísticos barriales, comunales, provinciales.

\section{Bibliografía}

Andrade, Susana, 1990, Visión Mundial: entre el cielo y la tierra, Ceplaes, Abya-Yala, Quito.

Andrade, Susana, 2004, Protestantismo Indigena, FLACSO, Abya-Yala, Quito.

Confederación de las Nacionalidades y Pueblos Indígenas del Ecuador, 1997, Propuesta del Estado plurinacional de la República del Ecuador, CONAIE, Quito.

2007, Plurinacionalidad, autogobierno, y territorio, CONAIE, Quito.

2007, Propuesta de la CONAIE frente a la asamblea constituyente: Principios y lineamientos para la nueva constitución del Ecuador por un Estado plurinacional, unitario, soberano, incluyente, equitativo, y laico, CONAIE, Quito.

2008, Libro sobre las nacionalidades y pueblos originarios del Ecuador, Imprenta Nuestra Amazonía, Quito.

Chala, J., 2009, Intervención en mesa de interculturalidad y ciudadanía, Seminario sobre políticas públicas e interculturalidad, Quito 25-26 junio.

Ecuador. Constitución del Ecuador, 1830: http://www.efemerides.ec/1/mayo/1830.htm

Ecuador, Constitución del Ecuador, 1998: http://www.ecuanex.net.ec/constitucion/indice.html

Jameson, Frederic, 1998, Estudios Culturales, Paidos, Buenos Aires.

Karankras, A., 2009, Intervención en mesa de Interculturalidad y ciudadanía, Seminario sobre políticas públicas e Interculturalidad, Quito 25-26 junio.

Macas, Luis, 2009, “Construyendo desde la historia: resistencia del movimiento indígena en el Ecuador", en: Acosta, Alberto (ed.), La plurinacionalidad, Abya Yala, Quito.

Moreno, Segundo, 1978, Sublevaciones indigenas en el Ecuador, PUCE, Quito.

Queiroz, João, 2009, Diversidad Biocultural y Adaptación al Cambio Climático. Ponencia presentada en el Seminario Políticas Públicas e Interculturalidad, junio 25-26, Quito.

Rodríguez, Lilia, 2009, Interculturalidad en salud reproductiva, percepciones de las mujeres indígenas y prácticas de salud en el hospital San Luis de Otavalo. Maestría en Antropología, Universidad Politécnica Salesiana, Quito.

Sousa Santos Boaventura, 2009, "Las paradojas de nuestro tiempo y la plurinacionalidad", en: Acosta, Alberto (ed.), La plurinacionalidad, Abya Yala, Quito.

Walsh, Catherine, 2009, Interculturalidad, Estado, Sociedad, Universidad Andina Simón Bolivar, AbyaYala, Quito. 